\title{
An exploratory study for investigating the critical success factors for cloud migration in the Saudi Arabian higher education context
}

\begin{abstract}
Saudi universities have at their disposal a huge number of low cost IT resources to aid in teaching, research and learning. By migrating to cloud services, Saudi universities will be moving data and programs from local servers to the internet, thereby providing users with the ability to access and share information at any time from multiple devices. The migration to cloud-based IT resources is not yet widespread in Saudi universities due to several challenges including security, legal policies and implementation. At present, there is lack of research and guidance for Saudi universities on how to overcome these challenges and how contextual factors can influence the successful migration to the educational clouds.
\end{abstract}

This research presents a framework for the successful migration to cloud technology in the Saudi Arabian universities. In this research, a set of key critical success factors (CSFs) were identified by synthesizing components from studies concerned with the migration of cloud for higher education and factors identified from the successful implementation of WBL (Web Based Learning) and ERP (Enterprise Resource Planning) on higher education in Saudi Arabia. Based on this knowledge, the proposed framework was evaluated via expert review and a survey by IT specialists from the Saudi universities. The initial CSFS were updated based on the expert reviews and the results were analysed. Based on the findings at this stage, additional CSFs were added to the framework as suggested by the experts. Subsequently, in order to confirm the reviewed CSFs, additional investigation via a structured online questionnaire was conducted and the outcome was analysed via one-sample t-test with the data integrity analysed via Cronbach's alpha. The outcome indicated the majority of CSFs to be statistically significant except the Physical Location CSF. Potential future study and contributions are discussed.

Keywords: Educational Clouds, success factors, Cloud migration, ICT Saudi Universities 


\section{Introduction}

Public service and higher education institutions play an important role in the growth of societies. As with commercial organisations nowadays, universities have become more reliant on Information and Communication Technology (ICT) and internet-based services to provide their stakeholders with the requested educational services. The higher education institutions have been compelled on using cutting-edge technologies in response to the growth of students numbers, competitive education environment and performance requirements. In fact, Some Universities are facing difficulty in providing scalable and flexible IT services for their stockholders. For instance, in traditional computer labs, there are many challenges present such as, limitation of lab hours and seats during the peak hours, repairing and maintaining computer labs, traveling to and from university, cost of outfitting traditional computer lab equipment (Truong et al. 2012).

Cloud computing is likely to be an attractive proposition to the educational establishments. Cloud has evolved from technologies such as virtualisation, grid computing, distributed computing, web 2.0 technologies, Service Oriented Architecture and utility computing. The National Institute of Standards and Technology (NIST) defines cloud computing as a model for enabling convenient, on-demand network access to a shared pool of configurable computing resources (e.g., networks, servers, storage, applications and services) that can be rapidly provisioned and released with minimal management effort or service provider interaction (Mell \& Grance 2011). The potential of cloud computing may include reducing IT costs while increasing productivity, scalability, and flexibility. In strive for developing the IT infrastructure in higher educational. Normally, IT services required by students, researchers and academics are requested from the IT Department. However, in cloud computing all these arrangements can be migrated to the cloud and the resources can be accessed from anywhere and at any time through the internet (Mathew 2012).

\subsection{Cloud computing status in the global higher education institutions}

Statistics show that $70 \%$ of higher education institutions in North America have moved (or are in the process of moving) their email systems to the cloud and 50\% have adopted a cloud-based collaboration system to improve information sharing across campus (Katz et al. 2009). According to a survey by Educause (Wheeler \& Waggener 2009), nearly all higher educational institutions in the West have a major interest in adopting cloud based solutions at least at the level of some departments.

For instance, the University of California (UC) at Berkeley, found cloud computing to be attractive for use in one of their courses which was focused exclusively on developing and deploying SaaS applications (Alshwaier 2012). Moreover, The Medical College of Wisconsin Biotechnology and Bioengineering Centre in Milwaukee found the use of cloud computing in their research very beneficial and provided them with massive computational power, which exceeded their own limited hardware power. Researchers at the Centre have been undertaking protein research which has been 
made more accessible to scientists from anywhere in the world. This is due largely to renting Google's cloud-based servers (Alharthi et al. 2015). Some universities have adopted cloud computing for economic reasons. The Washington State University's School of Electrical Engineering and Computer Science (EECS) has suffered cuts in its budget. However, the EECS claims that despite the challenging economic climate, cloud computing has actually enabled it to expand the services it offers to faculties and students (Sultan 2010).

\subsection{Cloud computing status in the Saudi higher education institutions}

The IT market in Saudi Arabia is considered as the largest IT market in the Gulf region, approximately valued at 3.4 billion dollars in 2008, and it is expected to rise to 5.6-billion-dollar by 2013 (Market Research Reports, 2009). The Saudi government has allocated 3.1 billion Saudi Riyals (SAR) as a fund to improve the education system. The fund was aimed to develop the educational institutions with the best technological and scientific facilities.

In Saudi Arabia, there are 27 government universities. Each university consists of colleges and departments that offer diplomas and bachelors, masters and $\mathrm{PhD}$ degrees; some colleges and departments also provide distance learning. Each university has two different sections, separated into male and female departments. In Saudi Arabia, each university has deanship of IT, which consists of different IT departments; their main role is providing ICT resources to the university stakeholders. Among these 27 universities only 8 universities are mature universities and around 19 universities are start-up universities. These new universities are scattered and located in some rural places, cities and villages with limited budget, Infrastructure and employees. Moreover, these start-up universities are still lacking web-based e-learning and teaching tools in comparison to the old universities in Saudi Arabia (Ministry of Higher Education, 2016). Currently in Saudi Arabia, the use of distance education is maturing. Yet, there is a room for improvement and expansion because only three universities: King Saud University in Riyadh, King Abdulaziz University in Jeddah, and King Faisal University in Al-Hasa have started to enhance e-learning and distance learning environment (Aljabre 2012). Therefore, Higher Education institutions in Saudi Arabia needs to evolve from traditional delivery methods, i.e. lecturing and tutoring to cloud based education in order to keep up with the latest educational services and tools.

Saudi universities are still slowly seeking to promote cloud based higher educational environment for e-learning and distance learning platforms, while it is widely being used in European and American universities to deliver better quality of higher education, (Odeh et al. 2014). Therefore, It is important to be aware of the challenges that hinder the cloud migration process the critical success factors (CSFs) for cloud migration in higher education in Saudi Arabia. From a strategic perspective, the successful implementation of cloud computing for higher learning in Saudi Arabia depends on the capabilities of top management, called the Deanship of IT to actively drive an organisational change 
through an official cloud migration strategy. The research aims to fill that gap in order to provide a conceptual framework investigating the successful factors for cloud migration designed especially for higher education in Saudi Arabia.

The paper is organised as follows: Section 2 presents an in-depth overview of the cloud computing paradigm within the Saudi Arabian context. The section further investigates the existing state-of-theart of cloud computing over the global stage. Section 4 then presents a critical analysis of various models and frameworks used to provide analyses of similar migration models. Section 5 then presents the core methodology proposed in this paper which presents a set of critical success factors (CFSs) that hold importance in facilitate cloud migration within the Saudi Arabian higher education context. Section 6 finally presents a critical analysis of the interview and survey outcomes before concluding with a set of future directions on this research.

\section{Literature review}

By using cloud services, enterprises can deploy their application systems over a group of independently managed resources. However, the majority of such organizations rely on their own custom needs which must be considered if they decide to use cloud-based systems (Jamshidi, 2013).

Migration to the cloud refers to the process of moving applications, data, servers, networks from inpremises to the cloud data centres. This migration of ICT to the cloud can be conducted partially on some systems of the organization. Alternatively, all the IT infrastructure can be migrated to the cloud (Buyya et al. 2008). However, the process of migration still imposes a diverse range of risks and issues which must be considered in the overall global context of this process. The most frequently reported challenge is how efficiently these risks and identified and moderated. The most important phase in this process, as reported by Buyya (2012), is encountered during the testing and validation phase of migration. The phase includes the identification of core migration risks which are then mitigated during the optimisation phase. The overall risk mitigation process can broadly be categorised into two main issues: general migration risks and security-related risks. The former risk types are further elaborated to address issues of economical evaluation (Mastroeni and Naldi, 2011), downtime prevention during migration (Svard et al., 2011), handling legacy applications (Beserra et al., 2012), cloud resource estimation (Vobugari et al., 2013) and application migration challenges (Kolb et al., 2015). Extending further into the former category of general migration risks, a number of sub-challenges are to be identified and resolved (Buyya, 2012). These include issues related to performance monitoring and any side-effects that the process/system might encounter to facilitate business continuity and disaster recovery. Moreover, standard compliance, government issues, licensing requirements and QoS-related parameters are also considered. 
On the security aspect, the requirements go deeper into issues originating from trust, privacy, auditing, and multi-tenancy as well as the impact of data leakage. On the security-related risks domain, a number of areas have been investigated in the literature. In case of disaster recovery, a completely separate response is required for cloud-based systems. Traditional systems are known to rely on system snapshots, TCP/IP baseline and replication to provide support in case of emergencies. (Chang, 2015) reported a novel domain of work on the cloud to support big data recovery by keeping redundant system snapshots at geo-located servers. On the aspect of Data Centre Network (DCN) security handling issues (Wang et al., 2015), focus has primarily been on addressing multi-tenant demands and DCN routing, public key cryptography and SSL protocol implementation for distributed environments (Zhao et al., 2014), implementation of Cloud Computing Adoption Framework (CCAF) and infrastructure security auditing are a few areas to be considered during a migration process (Chang et al., 2016). Security as a service has focussed more on issues of modelling the theory of planned behaviour to assess the readiness of people to adopt a new technological framework as that of cloud. However, the majority of research in the domain of security as service is limited to cloud services and hence the case would be substantially different in the case of migrating other services to the cloud. Moreover, the majority of migration and security risk-related research considers security and privacy-related variables as a single entity which may assume a different concept in case of educational institutions. Migrating a legacy system to a cloud-based system involves a number of procedures that must be undertaken in a sequential manner as advised by Buyya (2012). The process is termed as a seven-step model of migration into the cloud and starts with the migration assessment phase. This is followed by isolation of dependencies, environment mapping, making provision for lost functionalities, integrating cloud functionalities, testing and finally iteratively optimising.

The usage of cloud services in UK and European universities is growing dramatically in comparison with the Middle Eastern universities. The Middle East has just begun the initial phase in order to offer teaching through cloud computing (Weber 2011; Odeh et al. 2014). According to Odeh et al. (2014), the usage of cloud computing in higher education in Middle East region is at the early stages in comparison with the European Universities, which are widely using cloud nowadays. Zabadi (2015) has conducted a case study about eLearning in Saudi Arabia and mentions technical and telecommunication infrastructure as the first challenge (Zabadi 2015). Alshwaier (2012) has cited advantages of cost, efficiency, reliability, portability, flexibility, and security in adopting cloud for eLearning in Kingdom of Saudi Arabia (KSA) and says that cloud based learning management system (LMS) can automate the teaching process and can help in managing the growing number of students enrolling for higher education in KSA (Alshwaier 2012). He has also cited security, availability, vendor lock-in and unsolicited advertising as challenges for cloud-based education in KSA, but this study was not focused on finding a framework based on challenges or critical success factors. Any challenges and success measures, if understood soundly within the context of Saudi Arabian 
universities, are likely to increase the chances of successful migration of the cloud. This study was mainly done to show the advantages of cloud migration and give examples of cloud offerings for eLearning in KSA. Albalawi (2007) has carried out research on critical factors (CSFs) related to the implementation of web-based instruction by higher-education faculty at three universities in the Kingdom of Saudi Arabia, he has cited support from top management and attitude of instructors as among the critical factors for implementation of web-based instruction in Saudi Arabia apart from technological, performance and cultural factors. Since cloud computing is a part of web, these factors hold true for cloud as well. Al-Zoube (2009) has written about implementation of eLearning on the cloud in general but has not cited the critical factors to migrate to it.

ALdayel et al. (2011) discuss the Critical Success Factors of ERP: enterprise resource planning systems implementation and outsourcing in Higher Education in Saudi Arabia and they conclude that the most important success factor is project management (Sugawara \& Nikaido 2014). Alfaadel et al. (2012) investigated the success and the failure of IT projects in Saudi Arabia, he concluded that the most important factors that influence IT projects to fail in Saudi Arabia are poor planning, weak project management process, not enough resources allocated, office politics and, finally, the IT department and business users not speaking the same language. While, the most important CSFs to implement IT projects are: a clear statement of requirement, a competent project manager, top management support, organizational culture and clear project goals. Mansour (2013) in his case study on cloud adoption for Islamic University of Gaza in Palestine (IUG) has identified critical factors such as top management support, compliance and physical location and security. However, his study was only on one university in Palestine and he did not mention many challenges such as interoperability, service availability, disaster recovery and cultural issues such as privacy and attitude of users. M. Alotaibi (2014) concludes in his results that the perception, attitude and intention of Saudi people towards the adoption of cloud computing in Saudi Arabia is more important than technological factors like security and scalability, which are common to all countries (Alotaibi 2014).

There has been research conducted on finding critical factors for WBL, LMS, eLearning, ERP, ICT or virtual learning in Saudi universities (Asiri et al. 2012; Albalawi 2007; Yamin 2013). Little research has been conducted on cloud migration for Saudi higher education (M. Alabbadi 2011; Weber 2011; Odeh et al. 2014). However, none of the previous researchers has provided empirical investigation on the critical success factors to migrate to cloud computing paradigm.

Critical Success Factors (CSFs) in this study are defined as those issues that should be guaranteed by university for successful deployment of the cloud based services. In the context of higher education institutions in Saudi, the CSFs would be the set of enablers that should be provided by the University in order to implement the strategy in its educational process successfully and to improve the quality of higher education and research. These Critical Success Factors (CSFs) should be used to analyse the 
reasons behind the success and the failures of cloud deployments in similar educational institutions. Therefore, the study framework was constructed initially from secondary research review. The constriction was based on three phases. Based on the review of the existing literature, in phase 1: different cloud deployment related challenges in higher education settings globally and in Saudi Arabia context were identified from several researches, a review these challenges are presented in Alharthi et al (2015). Afterwards, the challenges were redefined as CSFs, which will enable cloud migration in higher education. Phase 2: involved finding successes factors of deploying similar technologies (WBL and ERP) to cloud computing in Saudi Arabia universities since there is no empirical data in the literature about success factors to implement cloud in Saudi Arabia Universities. In Phase3: A synthesis of the CSFs from WBL, Cloud, and ERP suitable for the Saudi higher education were selected and duplicated factors were eliminated. In addition, the proposed Success factors were grouped into technological and organizational sets of success factors. The initial proposed framework had ten critical factors as shown in Figure 1. These ten factors represent the t, organizational aspects related to higher education in Saudi Arabia.

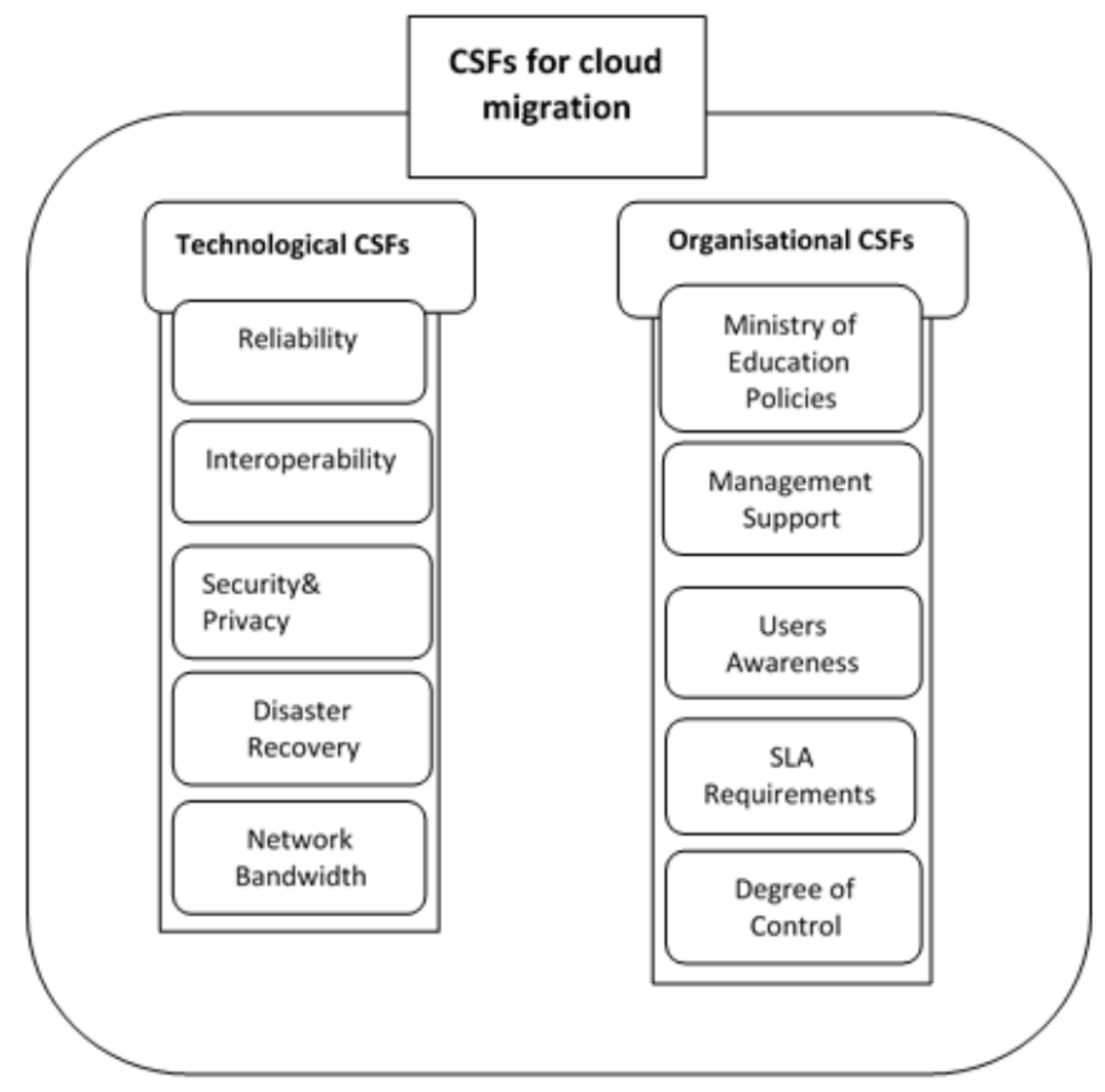

Figure 1: Success Factors for Cloud migration in Saudi Arabia universities based on literature 


\subsection{Technological Factors}

Technological factors are related to cloud architecture and decide the quality of service delivered:

\section{- Interoperability}

A universal set of standards and interfaces has not yet been defined for cloud based services, resulting in a significant risk of vendor lock-in. Higher education institutions should make sure that the Cloud based IT solutions must be interoperable and compatible between different providers; $24 / 7$ access to secure, reliable networks; and the ability to create, deliver, and share content campus-wide on any number of devices. (Cisco 2012; Educause 2010; Sqalli et al. 2012).

\section{- Reliability}

The University cloud-based services should be reliable and continuously available by providing redundant services, but the possibility still exists that the system could crash and leave clients with no way to access their saved data. Many existing cloud infrastructures leverage commodity hardware that is known to fail unexpectedly. A loss of Internet connectivity anywhere between a university customer and their cloud provider's network will cause interruptions of varying severity. It is important for the service to be reliable, if it is available. So without availability, reliability cannot be achieved. A cloud service should first be available in order to be reliable (Cisco 2011; Sultan 2010; Alshwaier 2012; Truong et al. 2012; Weber 2011; Shakeabubakor 2015).

\section{- Security \& Privacy}

Privacy and security are the top concerns for higher educational institutions planning to adopt cloud computing, due to the migration of sensitive data such as students' records, Researchers' Patents and Intellectual properties outside campus walls. Hence the importance of security and information privacy within University IT environment is crucial (Wheeler \& Waggener 2009; Albalawi 2007; Alshwaier 2012; Weber 2011).

\section{- Internet Bandwidth and Performance}

Cloud computing is a stateless system, as is the Internet in general. In order for communication to survive on a distributed system, it is necessarily unidirectional in nature. Most of remote requests used in the cloud is through HTTP messages like PUT and GET. The HTTP requests reach the provider and the service provider then sends a response. Low bandwidth would increase the latency of communications and the service would become very slow, if bandwidth is not increased. Therefore, Saudi universities should increase the Internet bandwidth in order to provide good cloud-base services to their stakeholders (Wheeler \& Waggener 2009; Albalawi 2007; Cisco 2011; Mansour 2013; Truong et al. 2012). 


\section{- Disaster recovery}

Saudi universities should ensure data recovery and business continuity back up plans, particularly regarding what they are responsible for during a disaster affecting their data centres. Universities have indirect administrative responsibility for the security of their data and applications and are accountable for data breaches and disaster recovery (Cisco 2011; Truong et al. 2012; Wheeler \& Waggener 2009).

\subsection{Organizational and Management Factors}

Organizational factors are related to the University culture and operational roles to migrate cloud computing. The factors are:

\section{- Top Management Support}

From a strategic perspective, the successful implementation of cloud solutions in Saudi Arabia depends on the capabilities of top leadership or management to drive the change from traditional deployment to cloud adoption through an official pro-cloud strategy (Albalawi 2007). The decision makers' awareness and consensus is vital. Their support will ensure what cloud services are needed and what type of cloud deployment is best for higher education settings. In order to do that the decision makers have to understand the benefits of cloud-based services, the value they can add to the educational services and how to migrate to cloud computing environment (Abeer I. ALdayel 2011; Mansour 2013).

\section{- Policies of Ministry of Education and legal compliance}

Since cloud computing is a relatively new technology, it will require changes to be made in Ministry of Higher Education policies and regulations and comply with legislations in Saudi government to ensure the safety of stakeholders' information. Saudi universities need to improve data policies in order to protect their sensitive information. This involves developing institution-wide cloud policies to help the institutions select the right sourcing and solutions that comply with the regulations in Saudi Arabia (Baki 2004; Krieger 2007).

\section{- Users awareness and training}

Successful implementation of any new technology requires proper plan to educate and increase the awareness of the stakeholders dealing with the technology and how to develop cloud solutions to serve the educational entities. Therefore, Saudi university IT department should provide their IT staff with training session on how to run cloud-based services and then introduce the cloud computing services to their stakeholders (academics and Students) and provide them with the guide needed in order to use the cloud services properly (Albalawi 2007) 
The motivation of academics to acquire the required competencies and to make use of cloud based IT for innovation and research is greatly influenced by encouragement from higher authorities and decision makers of Saudi universities. Saudi Higher Education institutions should offer incentives for their people to access cloud based services within a well-defined institutional framework. University decision makers and CIOs should make cloud solutions a part of personal work routines and teaching processes (Sugawara \& Nikaido 2014; Katz et al. 2009; Masud et al. 2012; Mitchell \& Cunningham 2014).

\section{- Customizable SLA requirements}

Saudi Universities need to be able to ensure that the service provider will continue to be there, even in face of changing market. Service level agreements (SLAs) are the contracts between the users of cloud services and the provider and it contains the expected uptime and performance of those services. Universities should consider those measurements and prepare list of customised requirements for each services they use and it needs to collect each department requirements in order to indicate them in the SLA to cover the end-user experience and the customer's operations (Masud et al. 2012; Onsman 2010; Song et al. 2013; Cisco 2012).

\section{- Degree of control}

The amount of control that the user has over the cloud environment varies greatly. In traditional IT environment, the consumer had full control over the services accessed. But the same is not true for the cloud services. For that reason, there is loss of control when universities migrate to the cloud, and it is the duty of the university CIO or management to make sure that the control is given to the right provider or decide what should be under their control and what can be migrated (Cisco 2011; Alshwaier 2012; Weber 2011).

\section{Research Methodology}

As the baseline nature of the research objectives of this investigation focussed mainly on data collected from individuals working in various IT deanships in Saudi universities, Methodological sequential triangulation (as illustrated in Figure 2) was deemed to be the most appropriate method to cross-confirm the initially proposed framework via mixed method approach (Qualitative and quantitative) (Denzin 1970). Data were collected from two different methods to compare and identify similar decision patterns (Golafshani 2003). The rational of using multiple sources of information or data is to produce similar results, which can enhance the validity and credibility of the findings (Fink 2003). An exploratory study was carried out to review and confirm the proposed success factors in the desk-based study. The experts review was mainly aimed at performing a critical review of the proposed framework based on the literature survey in order to develop the propose framework (i.e. 
delete, reorganize and add new success factors) by identifying and additional success factors unique to the Saudi university culture. Afterwards, an online survey was distributed to confirm the reviewed factors by experts, feedback from IT specialists working within the educational sector in Saudi Arabia was deemed crucial to confirm what was rudimentarily established via the earlier two stages (literature survey and expert interviews). The expert interview and the online questionnaire design process are further discussed in the following sections.

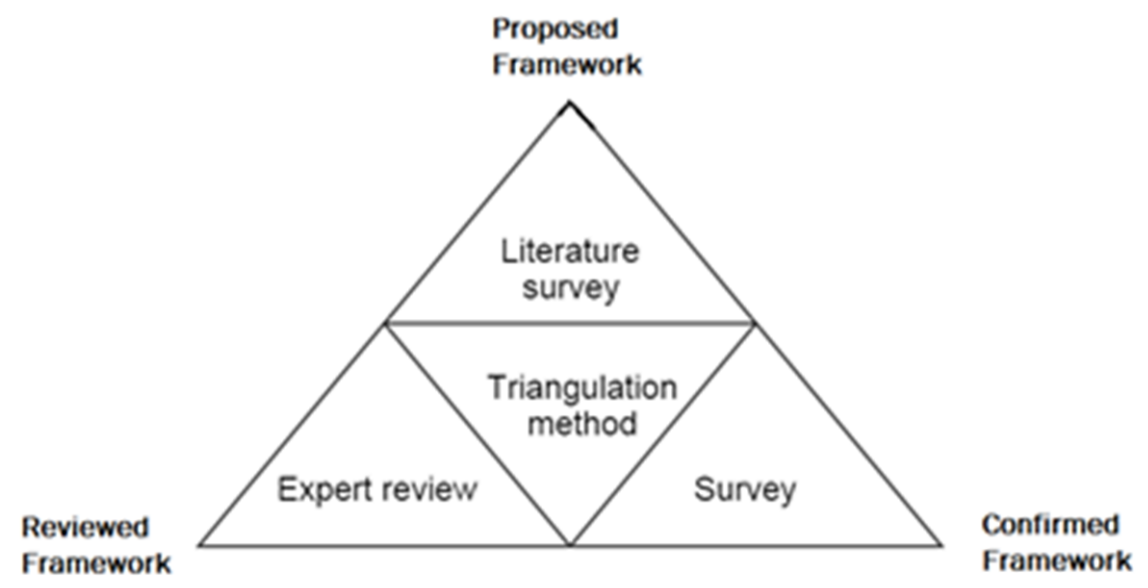

Figure 2: Triangulation confirmation of the proposed framework (Denzin 1970)

\subsubsection{Expert review design and analysis}

The expert interview involved semi-structured interview questions and discussions with experts from different IT departments in Saudi universities to improve and review the initial framework. Before interviewing the IT Experts in this study or distributing the questionnaire to participants, it needs to be planned to meet the ethical requirements of research. The ethical approval was sought and granted by the University of Southampton's ethics committee. The reference for the ethics application is 15707. This step was conducted by interviewing 13 IT experts from three Saudi Arabian universities. The experts in this study are people who work for the university IT projects for 5 years and more and those who are projects managers in the IT departments in the universities. The qualitative studies in expert sampling usually depend on their knowledge in the area being studied (Bhattachejee 2012). In this kind of sampling, the sample size depend on the saturation where no new knowledge can be gathered and this can be reached by twelve interviews (Guest 2006).

The interview questions were designed in a manner where Section 1 was focussed more on exploring the current status of cloud in Saudi universities, this section questions were open-ended questions whereas Section 2 - the Technological CSFs and Section 3 - the Organisational CSFs were more inclined on reviewing the importance of these two CSFs categories. Another question asked was focussed more on extracting user recommendations about any additional CSFs that could potentially 
lead to a better migration to the cloud. Moreover, the respondents were also queried about various types of cloud models that were more suitable to the socio-cultural environment of Saudi universities. The interview questions were reviewed by three experts. They gave valuable comments, which helped to make the questions clearer and more understandable.

The interviewees were taken from the IT deanship of Saudi universities and were interviewed over duration of three weeks. An iPhone was used to record the interviews via the Recorder application. The files recorded were then sent to the system desktop and the used by the NVivo-11 package to analyse the information saved within. A thematic analysis was carried out to examine themes within the interview qualitative results. According to the theme coding, all the proposed technological and organizational Success factors are considered important in affecting the migration to the cloud environment. However, some of the factors were renamed and the set of the factors were rearranged and correlated to each other as experts suggest that some of the proposed success factors are related to each other or form part of others. The semi-structured interview type was used to discover individual attitudes towards the problem at hand and getting an in-depth exploration of their experience in order to ascertain the existing cloud-migration status in their respective universities and review various critical success factors leading to successful migration to the cloud computing paradigm. As the participants were deemed to be experts, they were expected to (add/modify/delete) factors that may contribute to extend and update the initially proposed critical success factor framework.

\subsubsection{IT questionnaire design and analysis}

An online questionnaire was designed based on the outcome of the expert review in order to confirm the reviewed framework and make generalizations from a sample of the whole population. The questionnaire was distributed to confirm and quantify the findings from qualitative research. The participants in this survey were IT Specialists working for the university IT projects with minimum experience of two years. The questionnaire was used to capture undetected data such as participants' opinions and unobservable large population data. The questionnaire allowed participants to reply at their own convenience (Bhattachejee 2012). An online questionnaire was developed based on three sections: Demographic information and cloud status questions, technological success factors and organisational success factors. The first set was based on multiple choice whereas the remaining two were based on a 5-point Likert scale with ' 5 ' representing a strong agreement (Strongly Agree) and ' 1 ' representing a strong disagreement (Strongly disagree). Similar to the interviews, the online questionnaires were distributed in Saudi universities to anyone with two years or more of experience in IT deanships.

In quantitative research, calculating random sample size is usually involving mathematical preselected parameters. Two types errors are considered when calculating the minimum sample size. The more the sample size the less these two errors can be occurred (Banerjee et al, 2009). The first error must be 
considered is the first kind (the $\alpha$ ) and by convention is set to 0.05 for $95 \%$ confidence, the second kind (the $\beta$ ) and the power $(1-\beta)$ which was set to 0.9 for $10 \%$ of missing association. The effect size was also determined as large $(\mathrm{d}=0.8)$ because exploratory studies usually set at large effect size (Cohen 1992). To determine the minimum sample size for the survey participants, G* Power software was used and the calculation of t-test was performed to discover the difference in means form constant. The minimum sample size that resulted from the test was 19. The data was analysed both for its reliability and robustness. For its reliability, several psychometric tests have been developed with Cronbach's Alpha being one of them. The procedure in this method utilises all the variance and covariance information of the data to provide a unique estimate of its reliability (Zeller and Carmines, 1980 , p.56). Once the data is deemed reliable, it must still be compared against a "gold standard" which is generally a hypothesis made in the beginning of research. One-sample T-test is a technique often used to compare the data gathered against an expected outcome. For instance, the user input gathered in this study over a Likert scale is likely to be of significant nature for any factor if compared against a value higher than the neutral Likert number which is ' 3.5 ' on a scale of $1-5$ with 5 representing a strong user agreement.

\section{Study Results}

In this section the outcome of the qualitative and statistical analyses for quantitative study carried out on data gathered via mixed method approach (expert review and IT specialist questionnaire) is presented in order to confirm or reject the role of proposed CSFs in cloud migration in Saudi Arabian universities.

\subsection{Expert interview findings}

Based on the interview findings, 4 more CSFs were introduced as suggested by the expert respondents. In order to review the proposed framework of this research within the Saudi context, 13 IT experts working in 3 Saudi universities were recruited to provide their feedback. Out of these 3 universities only one had experience in existing cloud in-house infrastructure. The following bulletedsections further elaborate on the results of various questions asked during the interviews. The questions are grouped as exploratory questions about the current status of cloud migration within the context of Saudi Arabian universities.

\section{- Current Cloud Services and Deployments in Saudi Universities}

The historical outcome of the universities mainly focussed on private deployment and IaaS with a few emphasizing on Azure-based PaaS architecture trials. There were cases where in-house private cloud implementations were also setup. However, the majority of cloud-implementation interest encompassed older universities with a more stable administrative infrastructure. For instance, respondents from two start-up universities did not have any past experience or consideration of cloud- 
based paradigm, which may be attributed to the fact that these are very new universities with a low student intake and system load. This can further be understood from the fact that these smaller universities have a staff/student profile of around 20,000 whereas the former, has around 120,000 students and staff members. Despite the existing deployment infrastructure, there is however an expected future trend where the hybrid system would be covering community and private cloud settings between the universities and within the Saudi borders.

\section{- Scope of cloud migration}

On querying the type of work for which the cloud platforms are to be considered, the majority of respondents focussed on better service and hardware provision. There was also a mention of underutilisation of hardware resources where in-house servers were only used for about $15-20 \%$ of their original capacity. In cloud-implementation, a dynamic scaling model was likely to address this computational over or under-utilisation problem. Moreover, an offsite cloud implementation was also likely to save on physical space and energy requirement. Moreover, extensibility with local resources is also a problem where, once an additional need is envisaged, the delivery of additional hardware takes days if not weeks to arrive thereby wasting time and driving the costs up. On the information management and organisation aspect, the data centres would likely be purchased by the universities. How these data centres are going to be integrated in the existing setup would be subjective to their individual IT infrastructure and the skills of IT staff working in the particular university.

\section{- Potential challenges and issues in migration}

A question asked about the interviewees' opinion about the most challenges and issues were faced in the implementation of a cloud-based infrastructure. The foremost challenge was stated to be the best hardware selection and the selection of the best storage and server solutions. However, this required a careful assessment of the requirements of the entire stakeholder due to the mere fact that the system must also be compatible with all the existing resources and simple-enough for the users (IT specialists) to configure. The system should also be capable of automated control for best performance and can select the best networking architecture enabling virtual machines' load balancing effectively. Moreover, two of the respondents indicated challenges related to software/application compatibility which may be due to lesser OS versions and installed support libraries. Moreover, respondents' also pointed-out lack of human resources and experience required to manager and integrate cloud-services within the existing system architecture. For instance, licensing requirements and architectural restrictions may not allow the virtualisation on networked machines.

\section{- Performance of existing cloud infrastructure}


On the level of satisfaction achieved from the services provided by the cloud paradigm, there was a substantial support by the participants. The factors quoted were the agile and easy-to-use IT services compared to physical servers. It was deemed easier to implement new solutions due to the availability of abundant resources due to scalability and on-demand aspects integrated in the cloud architecture. This facilitated extensibility which is a core characteristic of growing enterprises similar to university throw new campuses and departments. Cloud made it possible to make such changes done within a matter of days. However, the time required to adjust to the new system did take a few years to reach a good service and performance level. The respondents were mainly satisfied in general as it facilitated work and made it possible to switch employee roles and reduce extra employment overhead. The respondents also quoted a solution implementation time saving of $3-5$ months. According to one of the respondents, universities as enterprises should focus on learning rather than issues of resource and IT management.

\subsubsection{Role of Technological and Organizational CSFs findings:}

The objective of questions in this section was to gain understanding of how these factors were important in a successful migration to the cloud and the underlying reason(s) behind these. In order to achieve this, the proposed technological and organizational success factors in Figure 1 were put-forth the interviewees in a bid to assess and evaluate the role of them in the migration of cloud computing within the Saudi universities. The themes covered under each factor are stated in the last column of Table 1Error! Reference source not found. which further explain the hidden and contributing aspects of each. Based on this response summary and themes, it can be seen that all the experts have unanimous agreement that the proposed factors are important except two (Network Bandwidth Requirement and User Awareness and Training).

Two out of the thirteenth respondents stated that 'Internet Bandwidth' is not important as quoted below by one Expert D:

"I think the existing bandwidth we have is enough. It is important because send and receive the data online and especially when you have other branches."

In terms of 'Staff Training and Awareness', three out of thirteen experts indicated that cloud training was required for the IT staff only before the migration process as quoted from Expert B:

"No not for the end users, they are smarter these days because of their engagements with the day-today online applications. However, IT Specialist need to be trained and this can be one important factor of migrating your system to cloud because you have a skilled team can supervise the new IT environment"

Table 1: Mixed method analysis of Experts' review 


\begin{tabular}{|c|c|c|c|}
\hline Codes (Factors) & Yes & No & Themes \\
\hline \multicolumn{4}{|c|}{ Technological Success Factors } \\
\hline Reliability & 13 & 0 & $90-99 \%$ up time \\
\hline Interoperability & 13 & 0 & $\begin{array}{l}\text { Cross-vendor migration may potentially } \\
\text { result in additional costs }\end{array}$ \\
\hline $\begin{array}{l}\text { Security and } \\
\text { privacy }\end{array}$ & 13 & 0 & $\begin{array}{l}\text { There is a decree that forbade data } \\
\text { outsourcing to anywhere outside Saudi } \\
\text { Arabia }\end{array}$ \\
\hline $\begin{array}{l}\text { Disaster } \\
\text { Recovery }\end{array}$ & 13 & 0 & $\begin{array}{l}\text { High costs related to in-house recovery } \\
\text { and backup resources }\end{array}$ \\
\hline $\begin{array}{l}\text { Network } \\
\text { Bandwidth } \\
\text { Requirement }\end{array}$ & 11 & 2 & $\begin{array}{l}\text { This is particularly a core requirement if } \\
\text { in-house implementation is to be done }\end{array}$ \\
\hline \multicolumn{4}{|c|}{ Organizational Success Factors } \\
\hline $\begin{array}{l}\text { Ministry of } \\
\text { Education } \\
\text { Policies }\end{array}$ & 13 & 0 & $\begin{array}{l}\text { Only one decree stating that the hosting } \\
\text { of government data internationally is } \\
\text { strictly prohibited }\end{array}$ \\
\hline $\begin{array}{l}\text { Management } \\
\text { Support }\end{array}$ & 13 & 0 & $\begin{array}{l}\text { The funds' authorisation originate from } \\
\text { top management called "administration } \\
\text { of purchase" which must overlook this } \\
\text { process }\end{array}$ \\
\hline $\begin{array}{l}\text { User Awareness } \\
\text { and Training }\end{array}$ & 10 & 3 & Focus more on IT specialists \\
\hline $\begin{array}{l}\text { SLA } \\
\text { Requirements }\end{array}$ & 13 & 0 & $\begin{array}{l}\text { Each university should have a } \\
\text { customised set of SLA requirements }\end{array}$ \\
\hline $\begin{array}{l}\text { Degree of } \\
\text { Control }\end{array}$ & 13 & 0 & $\begin{array}{l}\text { There must be a full control particularly } \\
\text { on sensitive information }\end{array}$ \\
\hline
\end{tabular}

\subsubsection{Recommendation of additional success factors}

Last Question in the interview was aimed at extracting recommendations about additional CSFs not mentioned and its relevance to the previous factors in the initial framework. The CSFs recommendations by experts are shown in Figure 3. 


\section{Additional CSFs as stated by experts}

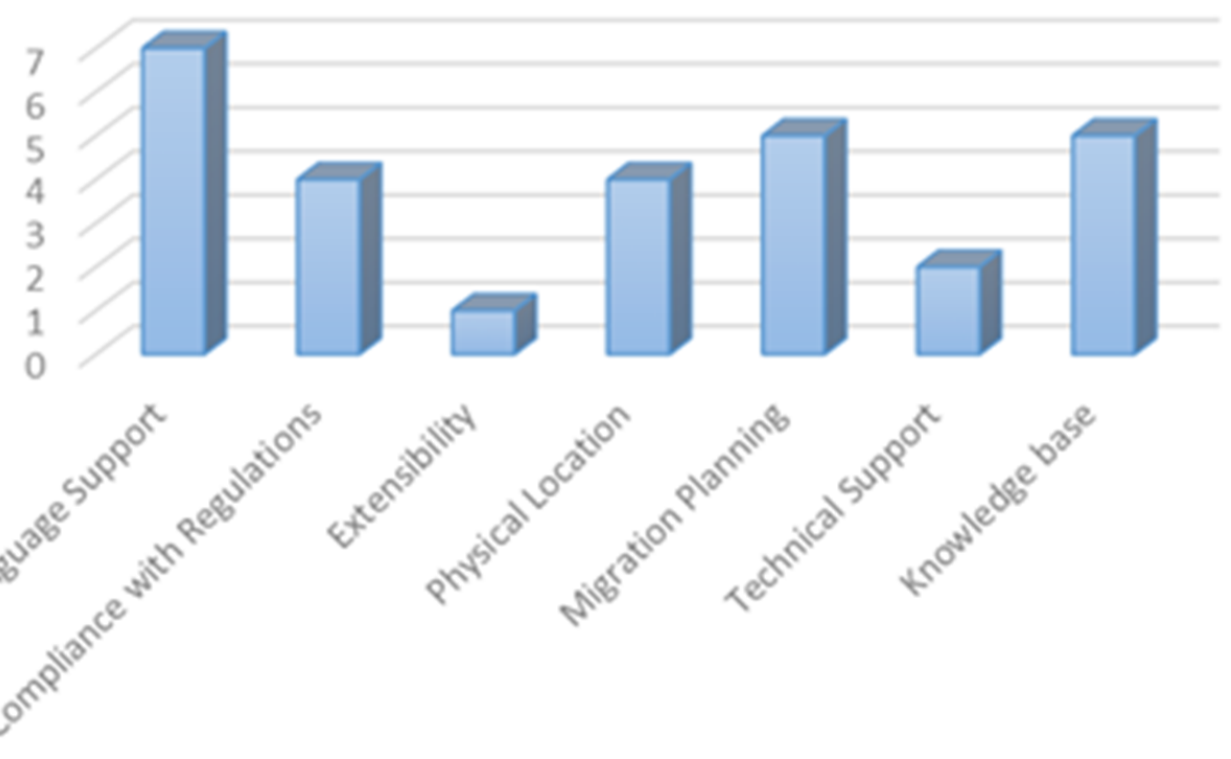

Figure 3: Recommended success factors by the respondents

The additional CSFs stated in Figure 3 were then cross-correlated with the initially proposed CSFs which are further discussed and categorised on user input (quoted) below.

One of the 7 experts supported Arabic language as quoted in the following manner by Expert F:

"I think supporting Arabic Language is important factor in different services such as Users interfaces for SAS apps Such as Office365, Web Interfaces."

Arabic language support has long been part of all major operating systems and support tools. As the cloud-based paradigm extends on the same baseline, it is imperative that this support is part of the overall SLA requirements. The language support aspect was further mentioned in conjunction with the overall technical support as evident in comments made by Expert $\mathrm{K}$ :

“... Arabic support and technical support and fast response within 24 hours and availability of $24 / 7 \ldots \cdots$

Compliance with regulations was another factor stated by the experts. The country is based on strong supervision of the government sector on all the educational and other public service sectors. There exists a Decree which inhibits the outsourcing of cloud and other IT infrastructure bearing critical data 
to external service providers. This factor was already proposed as Ministry of Education Policies however it was advised to be supported on national level via the government.

Quoted from Expert A:

"For Future Use of Public Cloud, I think Physical Location of data and which country it is located and what are the data policies regulation and policies is very important and what are the data protection policies applied in each country the data stored in."

Migration planning was suggested by 5 of the experts. Extending on this aspect and the previous responses, the following three sub-categories were understood to be an integral part of the migration planning factor:

- Knowledge-base: This context indicates building a strong repository containing information about service providers' products and prices, security and other best practices and organisationalspecific services for the overall migration process. This can be understood by a notable statement by Expert E:

"study the provider's performance; prices and the lesson learned from other consumers are very important factor."

This factor was included under "Migration Planning" due to the fact that any strategic decision or plan requires documentation of lessons learned in the form of a knowledgebase.

- IT training

Following-up on the knowledge-base, IT training can also form part of the overall migration plan as it must be performed prior to any migration activities taking place in order to facilitate appropriately trained staff to be available for the new system. This aspect was highlighted in one of the quotations by Expert $\mathrm{G}$ as follows:

“... IT Specialist need to be trained and this can be one important factor of migrating your system to cloud because you have a skilled time can supervised the new IT environment ..."

\section{- Management support}

The role of management support factor was unanimously supported by all the respondents which directly links to the overall migration planning as without management support, a plan cannot be executed. This aspect can further be ascertained by Expert F:

“ ... in any IT projects we provide the study we made and escalate it to the top management and The deanship of projects in the university and without their support the project will not be authorised ..."

Interoperability was originally proposed and unanimously agreed. Extensibility was quoted as one factor as follows by one of the experts (Expert L) 
"Extensibility is very important if you are deploying on in-house private cloud."

The factor can directly be relevant as systems that are scalable, are easier to manage and normally platform independent.

Physical Location was an additional factor stated and supported by 4 of the experts which correlates based on the fact that government regulations also emphasised as such. This was further evident from a quotation taken from Expert F:

"Physical location and compliance with Saudi Arabia data protection policies"

\subsection{IT Questionnaire Results}

The online questionnaire was aimed to confirm the result from the expert review in order to increase the credibility and validity of the data. Before distributed the questionnaire a pilot test of the questionnaire was administered to five IT practitioners with three years working experience in IT departments in Saudi Arabia university, who are computer science researchers now at the Brunel University and the University of Southampton to identify errors, avoid wrong design and predict possible problems. Afterwards, It was distributed to 55 respondents and only 41 individuals responded. The questionnaire was organised into three sections. The first section relates to demographic information as illustrated in Figure 4, while the second and third sections present closed questions on cloud migration success factors. In section one: The respondents to the questionnaire were working in IT deanships within Saudi universities with about $70 \%$ belonging to start-up colleges or small-scale institutions (aFigure 4). Hence, due to the nature of the majority of the students, the respondents' student and staff-base also predominantly belonged to institution with a less-than 25000 enrolled students or staff employed (b). The respondents predominantly had less than $2(30.43 \%)$ and between 6-10 years (23.93\%) of experience in the IT industry (c). Moreover, a wide majority (41\%) believed their institution to have migrated to a cloud-based setup within $1-5$ years where almost a third (34\%) indicated that uncertainty on the timescale of cloud migration (d). 


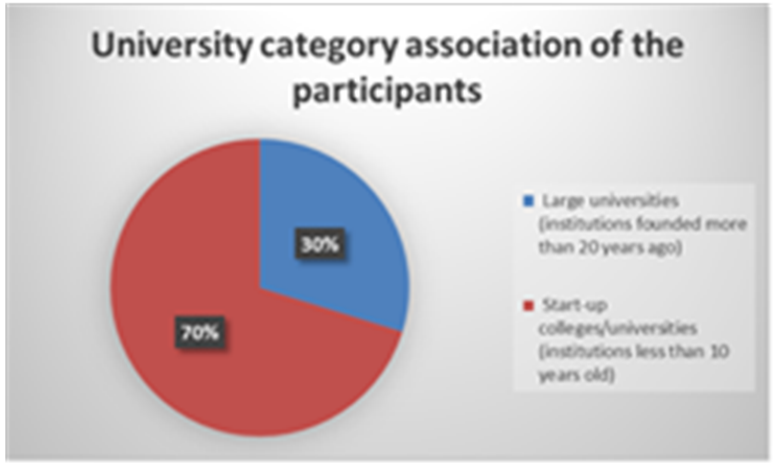

(a)

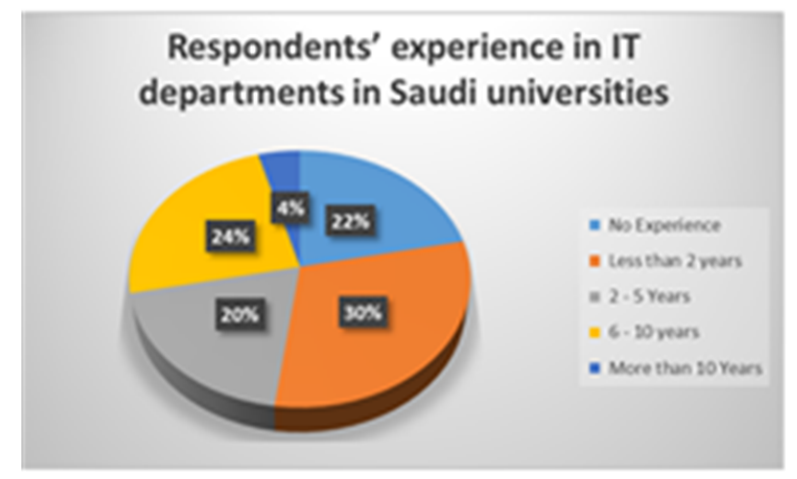

(c)

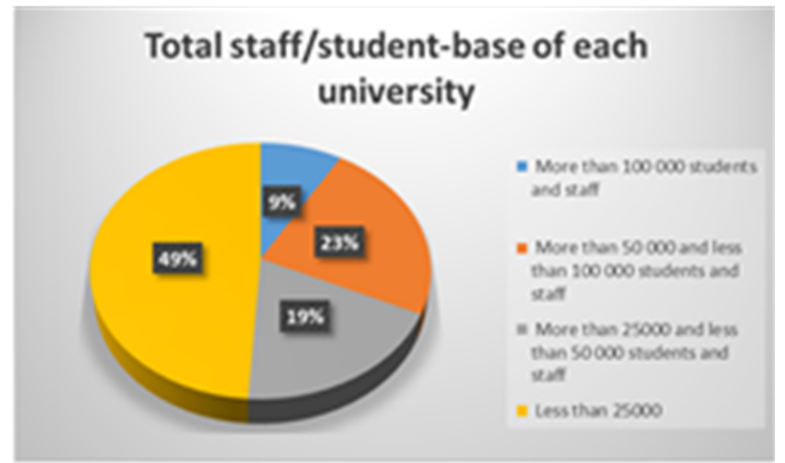

(b)

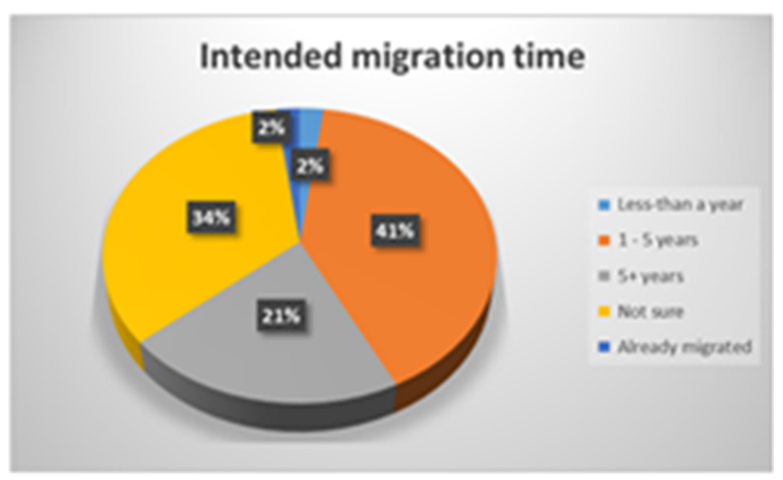

(d)

Figure 4: (a) A distribution of sample-based representing the division of respondents from various institutions in Saudi Arabia (b) The overall staff and student-based in numbers of universities to which the respondents belonged (c) Respondents' experience in IT departments in various Saudi universities (d) Percentage participants indicating intended time to cloud migration

In sections two and three questions, the respondents were asked about various factors that could lead to a successful migration of the cloud via close-ended questions. The data this collected was then analysed via SPSS statistical analysis software via a one-sample t-test measure. The question values for this test were defined over a Likert scale interval ranging from 5 representing strong agreement to 1 representing strong disagreement.

Before moving ahead with the main t-testing results, the data was analysed for reliability. A total of 41 IT specialists agreed to respond to the questions in the survey with the input from $95.1 \%$ being taken as complete and 2 data items discarded due to missing information see Table 2:

Table 2: Summary of the overall data validity

\begin{tabular}{|c|c|c|}
\hline \multicolumn{3}{|c|}{ Case Processing Summary } \\
\hline & $\mathrm{N}$ & $\%$ \\
\hline
\end{tabular}




\begin{tabular}{|c|c|c|c|}
\hline Cases & Valid & 39 & 95.1 \\
\cline { 2 - 4 } & Excluded & 2 & 4.9 \\
\cline { 2 - 4 } & Total & 41 & 100.0 \\
\hline \multicolumn{3}{|c|}{} \\
\hline
\end{tabular}

The data was further evaluated for its internal consistency via Cronbach's alpha to analyse how closely related a group of items were in the overall dataset. The measure was used in order to assess the reliability and consistency of the dataset. The function is written as a function of a number of values and the level of inter-correlation between these items as shown below (Zeller and Carmines, 1980, p.56):

$$
C^{\alpha}=\frac{N \cdot \bar{c}}{\bar{v}+(N-1) \cdot \bar{c}}
$$

In (1), $N$ is the total number of respondents, $\bar{c}$ is the inter-value correlation and $\bar{v}$ is the average variance over the entire dataset. Based on the equation, it can be understood that increasing the number of items will increase the overall $C^{\alpha}$ whereas an overall inter-value variance will result in a lower alpha value. The measure was hence used to evaluate the reliability and inter-value correlation of 24 question-variables with the outcome shown in Table 3: The Cronbach's Alpha value of 0.933 indicates a highly reliable dataset.

Table 3: Reliability statistics based on Cronbach's alpha measure

\begin{tabular}{|r|r|}
\hline \multicolumn{2}{|c|}{ Reliability Statistics } \\
\hline $\begin{array}{r}\text { Cronbach's } \\
\text { Alpha }\end{array}$ & N of Items \\
\hline .933 & 24 \\
\hline
\end{tabular}

Having analysed the dataset, the work was then extended to the findings of the quantitative data from the questionnaire respondents. The stage aimed to pinpoint factors with critical role in the migration to cloud-based services within the context of Saudi educational institutions. Table 4 contains the outcomes of the one-sample t-test analysis from the respondents' outcome. In order to assess the data, a Bonferri correction was used to ensure no false positives were induced in the data. In order to ensure this, a CSF variable was only deemed important if the $\mathrm{p}$-value of it was $<\alpha / n=0.05 / 24=0.0021$. This value indicates that the null value hypothesis was only rejected if the respective p-value was $<0.0021$. The one sample t-test value was assigned is 3.5 . This value was chosen on the basis 
that the majority of respondents would either agree or strongly agree with the role of a specific CSF variable or would be neutral. Any other selections would make it highly likely to reduce the mean of that variable to a value of less than 3.5. This aspect was evident from all the variables apart from the "physical location awareness" variable. Moreover, the statistical significance of this variable and the others was derived via the Sig (2-tailed) comparison against the Bonferri value of 0.0021 . The data in the above table showed all the factors were statistically significant apart from the "physical location awareness" variable which was greater than 0.0021. Apart from this CSF variable, all other values indicated the significance of the remaining 23 variables were statistically significant as all the values are less than 0.0021 .

Table 4: One-sample T-test Results

\begin{tabular}{|c|c|c|c|c|}
\hline Success Factors & Items & Mean & Sig (2-tailed) & Result \\
\hline \multicolumn{5}{|l|}{ Technological } \\
\hline \multirow{3}{*}{$\begin{array}{l}\text { 1. Security } \\
\text { (SE) }\end{array}$} & SE1 & 4.65 & $<0.001$ & Statistically significant \\
\hline & SE2 & 4.48 & $<0.001$ & Statistically significant \\
\hline & SE3 & 3.88 & .016 & Not statistically significant \\
\hline \multirow{4}{*}{$\begin{array}{l}\text { 2. Reliability } \\
\text { (RE) }\end{array}$} & RE1 & 4.65 & $<0.001$ & Statistically significant \\
\hline & RE2 & 4.58 & $<0.001$ & Statistically significant \\
\hline & RE3 & 4.45 & $<0.001$ & Statistically significant \\
\hline & RE4 & 4.25 & $<0.001$ & Statistically significant \\
\hline \multirow{4}{*}{$\begin{array}{l}\text { 3. Interoperability } \\
\text { (IN) }\end{array}$} & IN1 & 4.35 & $<0.001$ & Statistically significant \\
\hline & $\mathrm{IN} 2$ & 4.30 & $<0.001$ & Statistically significant \\
\hline & IN3 & 4.41 & $<0.001$ & Statistically significant \\
\hline & IN4 & 4.45 & $<0.001$ & Statistically significant \\
\hline \multicolumn{5}{|l|}{ Organizational } \\
\hline \multirow{3}{*}{$\begin{array}{ll}4 . & \text { SLA } \\
\text { Requirements } \\
\text { (SL) }\end{array}$} & SL1 & 4.30 & $<0.001$ & statistically significant \\
\hline & SL2 & 4.41 & $<0.001$ & statistically significant \\
\hline & SL3 & 4.56 & $<0.001$ & statistically significant \\
\hline \multirow{5}{*}{$\begin{array}{l}\text { 5. Migration Plan } \\
\text { (MP) }\end{array}$} & MP1 & 4.20 & $<0.001$ & Statistically significant \\
\hline & MP2 & 4.51 & $<0.001$ & Statistically significant \\
\hline & MP3 & 4.24 & $<0.001$ & Statistically significant \\
\hline & MP4 & 4.29 & $<0.001$ & Statistically significant \\
\hline & MP5 & 4.51 & $<0.001$ & Statistically significant \\
\hline \multirow{2}{*}{$\begin{array}{l}\text { 6. Compliance } \\
\text { with }\end{array}$} & CR1 & 4.39 & $<0.001$ & Statistically significant \\
\hline & CR2 & 4.37 & $<0.001$ & Statistically significant \\
\hline
\end{tabular}




\begin{tabular}{|l|l|l|l|l|}
\hline \multirow{3}{*}{$\begin{array}{l}\text { regulations } \\
(\mathrm{CR})\end{array}$} & $\mathrm{CR} 3$ & 4.24 & $<0.001$ & Statistically significant \\
\cline { 2 - 5 } & $\mathrm{CR} 4$ & 4.27 & $<0.001$ & Statistically significant \\
\cline { 2 - 5 } & $\mathrm{CR} 5$ & 4.46 & $<0.001$ & Statistically significant \\
\hline
\end{tabular}

\section{Discussion and conclusions}

The expert interviews were carried out with individuals from three different Saudi universities whereas the IT questionnaire was aimed at gathering information from IT specialists working the IT deanships of various Saudi universities. Based on the interview outcome $87.69 \%$ of the participants strongly supported 5 technological factors with just 2 saying no to the importance of network bandwidth requirement importance. Looking further into the details of these interviews, it was understood that reliability, security and privacy had a unanimous (100\%) support of the respondents with regards to the aspects of up-time, cross-vendor migration and government-level compliance. Security, for instance, has been supported by Alshwaier (2012) supported the importance of security and privacy by reporting on aspects of identification, authorisation, authentication, integrity, confidentiality, non-repudiation and availability with a focus on the educational cloud and e-learning. Similarly, importance of reliability and privacy have been reported in the work of Sultan (2010). The work reported reliability as a serious challenge within the cloud. This may be attributed to the fact that SLA requirements also commit predominantly on reliability processes as well. Additionally, interoperability and disaster recovery aspects were supported by $76.92 \%$ and $84.61 \%$ of the participants respectively. There was a bit of uncertainty in terms of the role of network bandwidth requirements where 2 of the respondents actually said no to its important with 1 being uncertain. In terms of reliability, work done by (Güner and Sneiders, 2014) reported on the aspects of reliability and availability to have a positive influence on the adoption of cloud computing.

In order to further investigate these CSFs, the questionnaire was used to confirm the CSFs via the expert reviews. Within the technological context, a number of questions covering the CSFs from the earlier interviews as well as additional factors pointed out by the respondents were queried as structured questions. The outcome (Error! Reference source not found.), measuring IT specialists' feedback showed that security and reliability to be the most sought-after CSFs with an average agreement score of 4.62 out of 5 . On the latter scale, privacy, disaster recovery, compatibility and extensibility showed an average score of 4.44 out of 5 . At a much lower agreement scale, interoperability, bandwidth, Arabic language integration received a value of 4.3. Ketel (2014) reported on the challenges exposed in the absence of sufficient internet bandwidth and dynamic storage allocation for disaster recovery as two substantially important aspects. The lowest scoring aspect was found to be of physical location which received an agreement score of 3.88 . 
Based on the analysis of organisations factors, it was understood that $84.61 \%$ of the respondents agreed to importance of the majority of organisational CSFs. Specifically, CSFs related to policies and managements support were emphasised unanimously. SLA requirements and degree of control were also supported by $92.3 \%$ and $84.61 \%$ of the respondents. Only the CSF of user awareness and training had negative and uncertain responses with $23.07 \%$ saying no and $30.76 \%$ showing uncertainty on the importance of this CSFs. Moreover, the IT staff training aspect is highlighted as well as CSF in the domain of Saudi Higher Education (Abeer I. ALdayel 2011)

Similar to the technological case, the organisation context was also evaluated over a Likert scale. The factor getting the highest agreement were technical support, staff training, and the knowledge base provision received the highest average agreement score of 4.51 out of 5. Similarly, the degree of control represented by data access control and the service knowledge aspect, received a score of 4.38 . Management support, knowledge-base, compliance, strategy planning received an agreement score of 4.25 out of 5 . The aspect of management support and knowledge base is in compliance with the work reported by Aldayel et al. (2011), reporting project management and top management commitment \& support bearing scores of 10.69 and 6.18 respectively on a scale of $0-11$. However, this work primarily focussed on ERP implementation in the Saudi context. Albalawi (2007) reported on the measure of Arabic language support which matches with the user feedback of its importance within the proposed cloud migration context.

The scores obtained both from technological and organisation aspects clearly indicate the importance of the majority of CSFs except the role of physical location which indicates that as far as the security, reliability and other "high-agreement" aspects are adhered to, the location aspect does not hold much importance as long as it is within the Saudi national borders. Based on their experience, the respondents indicated a number of additional CSFs belonging to both technological and organisation CSFs addressing the issues of Arabic language support, compliance with the regulations in Saudi Arabia, physical location, strategic planning, extensibility, technical support and the knowledge base. The questionnaire results further confirm these factors as CSFs as illustrated in Figure 5. 


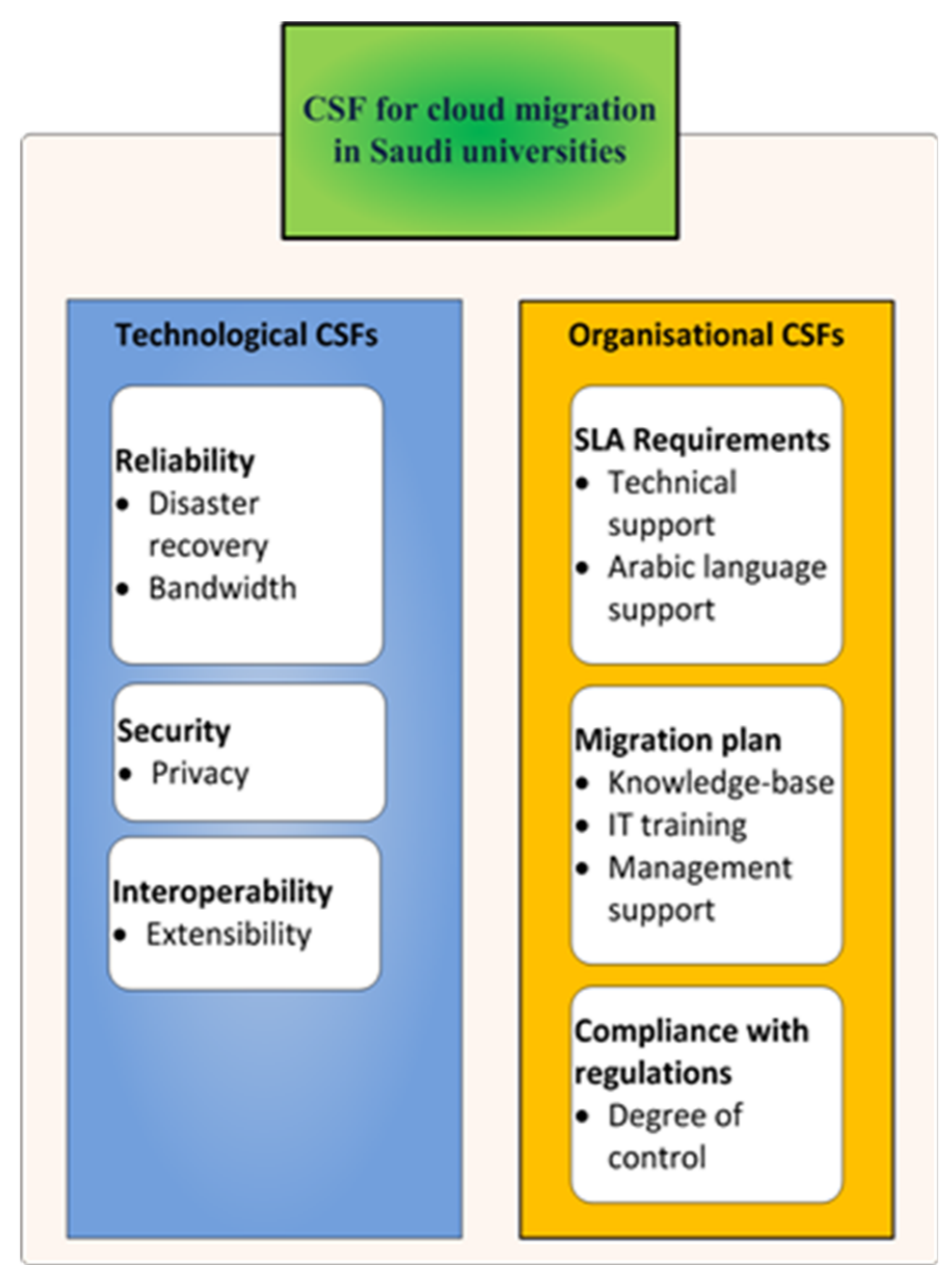

Figure 5: Confirmed CSFs for cloud migration

Furthermore, the results showed that security and privacy can be achieved in the Saudi context by providing adherence to the original government decree during the cloud migration process. The decree forbids outsourcing government data outside national borders. Moreover, reliability can be achieved by adhering to quality of service achieving $99.9 \%$ up time and interoperability is a crucial aspect as problems during cross-vendor migration may result in additional costs. If a decision is made to provide in-house cloud hosting services, aspects such as local backup and recovery may have substantially more costs. Also, as advised by the respondents, network bandwidth issues must be catered if the services are hosted in-house. Moreover, the management support aspect must originate via top-management personnel and user training must focus more on IT specialist only. Considering the university-level aspect, the organisations must have customisable SLA requirements depending upon the educational services required and the process should provide a full degree of control on the migration setup particularly on sensitive data. The sensitive data/information would be kept locally within the university whereas any other non-critical information would be shared at the Saudi national university level in order to promote knowledge and resources sharing. 
The confirmation of success factors for migrating ICT in Saudi universities in this proposed framework was a first step in our attempt to investigate the success factors enabling the migration process to the educational clouds in Saudi Arabia. We aim to utilise the confirmed success factors from the preliminary study to survey a larger sample of IT experts and decision makers at universities in several universities in Saudi Arabia and gulf region. The importance and impact of each component in our proposed framework will be analysed and their significance in the model validated through a test of the proposed success factors using Structure Equation Modelling (SEM). The framework can also be used in future studies on cloud computing migration in other sectors in the gulf region such as health and government agencies. The results from the full study will also contribute to the literature on cloud computing through empirical evidence from the study results and provide a potential of success rate of cloud computing migration project which can help the decision making process whether to migrate or not. The results from the proposed study will also provide IT practitioners and cloud services providers valuable empirical data that can be leveraged in hiring and advertising cloud computing projects.

\section{References}

Abeer I. ALdayel, M.S.A.A.S.A.-M., 2011. No Title. Journal of Information Technology and Economic Development, 2(2), pp.1-16. Available at: http://crawl.prod.proquest.com.s3.amazonaws.com/fpcache/c0e37e549aaedf5dbcb40ba14b6b3d 5e.pdf?AWSAccessKeyId=AKIAJF7V7KNV2KKY2NUQ\&Expires $=1463379124 \&$ Signature $=y$ pL\%2F3fn5\%2BE1rXJk\%2BsLSHPx9buao\%3D.

Alabbadi, M., 2011. Cloud computing for education and learning: Education and learning as a service (ELaaS). 14th International Conference on Interactive Collaborative Learning (ICL2011), (September), pp.589-594.

Albalawi, M., 2007. Critical factors related to the implementation of web-based instruction by highereducation faculty at three universities in the Kingdom of Saudi Arabia.

Alfaadel, F., Alawairdhi, M. \& Al-Zyoud, M., 2012. Success and failure of IT projects: a study in Saudi Arabia. In Proceedings of the 11th WSEAS international conference on Applied Computer and Applied Computational Science. pp. 77-82.

Alharthi, A. et al., 2015. An Overview of Cloud Services Adoption Challenges in Higher Education Institutions. In Proceedings of the 2nd International Workshop on Emerging Software as a Service and Analytics. SCITEPRESS - Science and and Technology Publications, pp. 102-109. Available at: 
http://www.scitepress.org/DigitalLibrary/Link.aspx?doi=10.5220/0005529701020109.

Aljabre, A., 2012. An exploration of distance learning in Saudi Arabian universities: Current practices and future possibilities. International Journal of Instructional Technology and Distance Learning, 9(2), pp.21-28.

Alotaibi, M.B., 2014. Exploring Users Attitudes and Intentions Toward the Adoption of Cloud Computing in Saudi Arabia: an Empirical Investigation. Journal of Computer Science, 10(11), pp.2315-2329.

Alshwaier, A., 2012. A New Trend for E-Learning in KSA Using Educational Clouds. Advanced Computing: An International Journal, 3(1), pp.81-97.

Al-Zoube, M., 2009. E-Learning on the Cloud. Int. Arab J. e-Technol., 1(2), pp.58-64.

Asiri, M.J. et al., 2012. Factors Influencing the Use of Learning Management System in Saudi Arabian Higher Education: A Theoretical Framework.

Baki, R., 2004. Gender-segregated education in Saudi Arabia: Its impact on social norms and the Saudi labor market. Education Policy Analysis Archives, 12.

Banerjee, A., Chitnis, U.B., Jadhav, S.L., Bhawalkar, J.S. and Chaudhury, S., 2009. Hypothesis testing, type I and type II errors. Industrial psychiatry journal, 18(2), p.127.

Beserra, P.V., Camara, A., Ximenes, R., Albuquerque, A.B. and Mendonca, N.C., 2012, September. Cloudstep: A step-by-step decision process to support legacy application migration to the cloud. In 2012 IEEE 6th International Workshop on the Maintenance and Evolution of Service-Oriented and Cloud-Based Systems (MESOCA) (pp. 7-16). IEEE.

Bhattachejee, A., 2012. Social Science Research: Principles, Methods, and Practices,

Buyya, R., Yeo, C.S. \& Venugopal, S., 2008. Market-Oriented Cloud Computing: Vision, Hype, and Reality for Delivering IT Services as Computing Utilities. 2008 10th IEEE International Conference on High Performance Computing and Communications, pp.5-13. Available at: http://ieeexplore.ieee.org/lpdocs/epic03/wrapper.htm?arnumber=4637675 [Accessed July 10, 2014].

Buyya, R., Pandey, S. \& Vecchiola, C., 2012. Market-Oriented Cloud Computing and the Cloudbus Toolkit. , pp.1-25.

Cisco, 2012. Cloud 101: Developing a Cloud-Computing Strategy for Higher Education. October.

Cisco, 2011. Cloud Computing in Higher Education : A Guide to Evaluation and Adoption.

Cohen, J., 1992. A power primer. Psychological bulletin, 112(1), p.155.

Chang, V. (2015) 'Towards a Big Data system disaster recovery in a Private Cloud', Ad Hoc Networks, 35 , pp. 65-82. 
Chang, V., Kuo, Y.-H. and Ramachandran, M. (2016) 'Cloud computing adoption framework: A security framework for business clouds', Future Generation Computer Systems, 57, pp. 24-41.

Denzin, N.K., 1970. The research act: A theoretical introduction to sociological methods, Transaction publishers.

Educause, 2010. Shaping the Higher Education Cloud. Readings, (May).

Fink, A., 2003. The Survey Handbook 2nd ed., SAGE Publications.

Golafshani, N., 2003. Understanding Reliability and Validity in Qualitative Research. The Qualitative Report, 8, pp.597-606.

Guest, G., 2006. How Many Interviews Are Enough?: An Experiment with Data Saturation and Variability. Field Methods, 18(1), pp.59-82.

Güner, E.O. and Sneiders, E., 2014. Cloud Computing Adoption Factors in Turkish Large Scale Enterprises. In PACIS (p. 353).

Jamshidi, P., Ahmad, A. and Pahl, C., 2013. Cloud migration research: a systematic review. IEEE Transactions on Cloud Computing, 1(2), pp.142-157.

Katz, R.N., Goldstein, P.J. \& Yanosky, R., 2009. Demystifying Cloud Computing for Higher Education Highlights of Cloud Computing. Educause Research Bulletin, 2009.

Ketel, M., 2014. E-learning in a cloud computing environment. In IEEE SOUTHEASTCON 2014.

Kolb, S., Lenhard, J. and Wirtz, G., 2015, June. Application Migration Effort in the Cloud-The Case of Cloud Platforms. In 2015 IEEE 8th International Conference on Cloud Computing (pp. 41-48). IEEE.

Krieger, Z., 2007. Saudi Arabia puts its billions behind Western-style higher education. The Chronicle of Higher Education, pp.1-6.

Mansour, A.J., 2013. The Adoption of Cloud Computing Technology in Higher Education Institutions : Concerns and Challenges.

Masud, A.H., Yong, J. \& Huang, X., 2012. Cloud Computing for Higher Education: A roadmap. In Proceedings of the 2012 IEEE 16th International Conference on Computer Supported Cooperative Work in Design, CSCWD 2012. pp. 552-557.

Market Research Reports. (2009). Saudi Arabia Information Technology Report Q2 2009. Retrieved 1 April, 2011, from: http://www.companiesandmarkets.com/Summary-Market- Report/saud iarabia-information-technology-report-q2-2009-80057.

Mathew, S., 2012. Implementation of Cloud Computing in Education - A Revolution. International Journal of Computer Theory and Engineering, 4(3), pp.473-475. Available at: http://www.ijcte.org/show-42-484-1.html. 
Mell, P. \& Grance, T., 2011. The NIST Definition of Cloud Computing Recommendations of the National Institute of Standards and Technology. Nist Special Publication, 145, p.7. Available at: http://www.mendeley.com/research/the-nist-definition-about-cloud-computing/.

Ministry of Higher Education. (2016). Saudi Government universities. Retrieved 3 May, 2016, from: https://www.mohe.gov.sa/en/studyinside/Government-Universities/Pages/default.aspx.

Mitchell, A. \& Cunningham, L., 2014. Impact of cloud computing in Ireland's institutes of higher education. , pp.1-11.

Odeh, M., Warwick, K. \& Cadenas, O., 2014. Major Differences of Cloud Computing Adoption in Universities : Europe vs . Middle East. , 5(12), pp.948-952.

Onsman, A., 2010. Dismantling the perceived barriers to the implementation of national higher education accreditation guidelines in the Kingdom of Saudi Arabia. Journal of Higher Education Policy and Management, 32(5), pp.511-519.

Shakeabubakor, A., 2015. Cloud Computing Services and Applications to Improve Productivity of University Researchers. International Journal of Information and Electronics Engineering, 5(2), pp.153-157. Available at:

$\mathrm{http}: / / \mathrm{www}$. ijiee.org/index.php? $\mathrm{m}=$ content\&c=index $\& \mathrm{a}=$ show $\&$ catid= $=50 \& \mathrm{id}=566$.

Song, S., Shin, S. \& Kim, J., 2013. A study on method deploying efficient cloud service framework in the public sector. ... Communication Technology (ICACT), ..., pp.33-38. Available at: http://ieeexplore.ieee.org/xpls/abs_all.jsp?arnumber=6488135.

Sqalli, M.H. et al., 2012. UCloud: A simulated Hybrid Cloud for a university environment. In 2012 IEEE 1st International Conference on Cloud Networking (CLOUDNET). IEEE, pp. 170-172.

Sugawara, E. \& Nikaido, H., 2014. Properties of AdeABC and AdeIJK efflux systems of Acinetobacter baumannii compared with those of the AcrAB-TolC system of Escherichia coli. Antimicrobial agents and chemotherapy, 58(12), pp.7250-7. Available at: http://stacks.iop.org/1751$8121 / 44 / \mathrm{i}=8 / \mathrm{a}=085201 ? \mathrm{key}=$ crossref.abc74c979a75846b3de48a5587bf708f.

Sultan, N., 2010. Cloud computing for education: A new dawn? International Journal of Information Management, 30, pp.109-116.

Svard, P., Tordsson, J., Hudzia, B. and Elmroth, E., 2011, November. High performance live migration through dynamic page transfer reordering and compression. In Cloud Computing Technology and Science (CloudCom), 2011 IEEE Third International Conference on (pp. 542-548). IEEE.

Truong, H.-L. et al., 2012. Cloud computing for education and research in developing countries. $L$. 
Chao, Cloud Computing for Teaching and Learning: Strategies for Design and Implementation, pp.64-80.

Vobugari, S., Somayajulu, D.V., Subraya, B.M. and Srinivasan, M.K., 2013, June. A roadmap on improved performance-centric cloud storage estimation approach for database system deployment in cloud environment. In 2013 IEEE 14th International Conference on Mobile Data Management (Vol. 2, pp. 182-187). IEEE.

Wang, B., Qi, Z., Ma, R., Guan, H. and Vasilakos, A. V. (2015) 'A survey on data center networking for cloud computing', Computer Networks, 91, pp. 528-547.

Weber, A.S., 2011a. Cloud Computing in Education in the Middle East and North Africa ( Mena ) Region : Can Barriers Be Overcome? The 7th International Scientific Conference eLearning and Software for Education Bucharest April 28292011.

Weber, A.S., 2011b. Cloud Computing in Education in the Middle East and North Africa ( Mena ) Region : Can Barriers Be Overcome? «Cloud Computing in Education in the Middle East and North Africa ( Mena ) Region : Can Barriers Be Overcome ?» Africa ( Mena ) Region : Can Bar.

Wheeler, B. \& Waggener, S., 2009. Above-Campus Services: Shaping the Promise of Cloud Computing for Higher Education. Educause Review, 44(december 2009), p.10.

Yamin, M., 2013. A Socio-cultural Overview of E-learning in Saudi Arabia. International Journal of Emerging Technology and Advanced Engineering, 3(12), pp.10-12.

Zabadi, A., 2015. THE IMPLEMENTATION OF E-LEARNING IN HIGHER EDUCATION IN SAUDI ARABIA: U.B.T. - A CASE STUDY., 3(February), pp.1-15.

Zhao, J., Wang, L., Tao, J., Chen, J., Sun, W., Ranjan, R., Kołodziej, J., Streit, A. and Georgakopoulos, D. (2014) 'A security framework in G-Hadoop for big data computing across distributed Cloud data centres', Journal of Computer and System Sciences, 80(5), pp. 994-1007.

Zeller, R.A. and Carmines, E.G., 1980. Measurement in the social sciences: The link between theory and data. CUP Archive. 